\title{
EFFICACY OF MAGNESIUM SULPHATE AS ADJUVANT TO BUPIVACAINE FOR LOCAL WOUND INFILTRATION FOLLOWING ELECTIVE ABDOMINAL SURGERIES
}

\author{
Rohit Kumar1, Saroja V. Sharma²
}

${ }_{1}^{1}$ Postgraduate Student, Department of Anaesthesiology, Kasturba Medical College, Mangalore.

2Professor and Former HOD, Department of Anaesthesiology, Kasturba Medical College, Mangalore.

\section{ABSTRACT}

\section{BACKGROUND}

Aims- Effective postoperative pain management minimises patient's suffering, facilitates rapid recovery, allowing early discharge from hospital and decreases hospital cost. This study compares analgesic efficacy of surgical wound infiltration with bupivacaine and a combination of bupivacaine with magnesium sulphate for postoperative analgesia in patients undergoing elective abdominal surgery.

Settings- Prospective, randomised, double-blind and controlled clinical study.

\section{MATERIALS AND METHODS}

64 patients of ASA Grade I and II, aged 18 - 75 years, weighing 40 - 70 Kgs scheduled for lower abdominal surgeries of 40 - 60 mins duration under GA were included. At the conclusion of the surgery, patients in Group B ( $\mathrm{n}=32$ ) received $10 \mathrm{~mL}$ of $0.5 \%$ bupivacaine $(50 \mathrm{mg})$ with $10 \mathrm{~mL}$ of normal saline and Group BM ( $\mathrm{n}=32)$ received $10 \mathrm{~mL}$ of $0.5 \%$ bupivacaine $(50 \mathrm{mg})$ and $1 \mathrm{~mL}$ of $50 \%$ of magnesium sulphate $(500 \mathrm{mg}$ ) with $9 \mathrm{~mL}$ normal saline for wound infiltration. They were evaluated for postoperative pain at $1,2,4,6,8,12$ and 24 hrs. with Visual Analogue Scale. Time of first rescue analgesia with IM tramadol 50 mg when VAS was more than 5 or on patient demand and total tramadol requirement in $24 \mathrm{hrs}$. were noted.

\section{RESULTS}

Mean postoperative VAS scores at $4^{\text {th }} \mathrm{hr}$. in Group B and BM were 5.09 and $2.91(\mathrm{p}=0.000 \mathrm{HS})$, at $6^{\text {th }}$ hr. VAS scores in Group B and BM were 4.31 and 3.34 ( $p=0.039$ Sig), at 24th $\mathrm{hr}$. VAS scores in Group B and BM were 4.31 and 3.44 ( $p=0.018$ Sig). Group BM had lower VAS scores and better postoperative pain relief at $4^{\text {th }}, 6^{\text {th }}$ and $24^{\text {th }}$ hrs. when compared to Group B. The mean time of first rescue analgesic in Group B and Group BM was at $4.29 \mathrm{hr}$. ( \pm 1.04$)$ and $6.91 \mathrm{hr}$. ( \pm 1.65$)$ respectively (p=0.000 HS). Total tramadol consumption in postoperative period was more in Group B compared to Group BM 175.00 mg ( \pm 38.10$)$ and $119.53 \mathrm{mg}( \pm 47.83)$ respectively, $(\mathrm{p}=0.000 \mathrm{HS})$.

\section{CONCLUSION}

Timing of the first rescue analgesic requirement increased as well as total rescue analgesic consumption in first twenty-four hours decreased. The technique is simple, relatively non-invasive, quickly performed, cost effective and is useful as component of multimodal analgesia.

\section{KEYWORDS}

Postoperative Pain, Local Anaesthetics, Wound Infiltration, Bupivacaine, Magnesium Sulphate.

HOW TO CITE THIS ARTICLE: Kumar R, Sharma SV. Efficacy of magnesium sulphate as adjuvant to bupivacaine for local wound infiltration following elective abdominal surgeries. J. Evolution Med. Dent. Sci. 2017;6(46):3614-3618, DOI: $10.14260 /$ Jemds/2017/779

\section{BACKGROUND}

The International Association for the Study of Pain has defined the experience of pain as complex, multifaceted and an unpleasant sensory and emotional experience. ${ }^{1}$

Postoperative pain management is an essential part of modern anaesthetic practice. Effective postoperative pain management decreases suffering, reduces cardiorespiratory, endocrinological, metabolic morbidity, facilitates rapid recovery of the patient allowing early discharge from hospital and minimises hospital cost. Multimodal analgesia combines multiple analgesics, which act at different sites in the nervous system by various mechanisms resulting in synergism of

Financial or Other, Competing Interest: None.

Submission 01-05-2017, Peer Review 26-05-2017,

Acceptance 01-06-2017, Published 08-06-2017.

Corresponding Author:

Dr. Saroja V. Sharma,

\#1 A Deccan Corner, Vas Lane,

Mangalore-575002, Karnataka.

E-mail: saroja_1949@yahoo.co.in

DOI: $10.14260 /$ jemds $/ 2017 / 779$ analgesia with minimal adverse effects of individual analgesics.

Infiltration of the surgical incision with local anaesthetics is useful adjunct in multimodal analgesia which is simple, inexpensive, safe, has predictable analgesic properties and avoids undesirable side-effects of parenteral analgesics, central neuraxial block and plexus blocks.

Local anaesthetics inhibit the transmission of noxious impulses form the site of injury and modulate peripheral pain transduction..$^{2}$ As a major proportion of pain originates from the surgical incision, the use of incisional infiltration with longer acting local anaesthetics with or without additives or administration of local anaesthetics by direct placement of catheter into the wound has become an important component of multimodal analgesia. Analgesic property of magnesium sulphate due to its NMDA receptor antagonist activity is utilised for providing pre-emptive analgesia by various routes. ${ }^{3}$ Our study objectives was to assess and compare analgesic efficacy of local infiltration of surgical wound with bupivacaine, the bupivacaine with magnesium sulphate for 
postoperative analgesia for patient undergoing abdominal surgery.

\section{MATERIALS AND METHODS}

A prospective, randomised, double-blind, controlled clinical study, following approval of Institutional Ethics Committee and written and informed consent, sixty-four patients of either gender belonging to ASA Grade I and II, aged 18 to 75 years, weighing 40 - $70 \mathrm{Kgs}$, scheduled for elective abdominal surgery under general anaesthesia were included. Patients exhibiting hypersensitivity to local anaesthetics or adjuvants, heart block, dysrhythmia, uncontrolled/labile hypertension, severe systemic disease, coagulation disorders, h/o of epilepsy/neurological disorders and psychiatric illnesses that would interfere with perception and assessment of pain were excluded.

Each patient underwent thorough pre-anaesthetic evaluation including history, general physical examination and basic laboratory investigations. Haemoglobin estimation, complete blood count, blood sugar, blood urea, creatinine, coagulation parameters, urine analysis, chest x-ray and ECG were obtained. The patients were educated about VAS score (Visual Analog Scale) for assessment of intraoperative and postoperative pain where $0=$ no pain, $1-3=$ mild pain, $4-6=$ moderate pain, $7-9=$ severe pain and $10=$ worst pain imaginable and were instructed to demand analgesia when needed. Preoperative baseline VAS scores were recorded.

Patients received $0.2 \mathrm{mg} / \mathrm{kg}$ diazepam and ranitidine 150 mg orally the previous night. Standard ASA fasting guidelines was followed. On the morning of surgery, venous access was established with 18-gauge Venflon cannula on the dorsum of the non-dominant hand after local infiltration. Patients were pre-hydrated with $15 \mathrm{~mL} / \mathrm{kg}$ of Lactated Ringer's solution, infused over 15 mins. Standard anaesthesia monitoring included measurement of non-invasive automated blood pressure, pulse oximetry, 5-lead ECG and heart rate. Baseline values were recorded preoperatively.

Patients received IV midazolam $0.02 \mathrm{mg} / \mathrm{kg}$, fentanyl 2 $\mu \mathrm{g} / \mathrm{kg}$ and glycopyrrolate $0.2 \mathrm{mg}$ as premedication.

Patients were assigned to two groups by computer randomisation in which computer has generated some random numbers, first 32 was allocated in Group B and rest in Group BM. Group B ( $\mathrm{n}=32)$ received $50 \mathrm{mg}$ of bupivacaine $(10 \mathrm{~mL})$ made up to $20 \mathrm{~mL}$ with $10 \mathrm{~mL}$ NS. Group BM $(\mathrm{n}=32)$ received $50 \mathrm{mg}$ of bupivacaine $(10 \mathrm{~mL})$ and $500 \mathrm{mg}$ of magnesium sulphate ( $1 \mathrm{~mL}$ of $50 \%$ ) made up to $20 \mathrm{~mL}$ by adding $9 \mathrm{~mL}$ of NS. The study drugs were prepared by an independent anaesthesiologist, who did not participate in the subsequent study.

Following pre-oxygenation, general anaesthesia was induced with IV propofol $2 \mathrm{mg} / \mathrm{kg}$ and tracheal intubation was facilitated with suxamethonium $1.5 \mathrm{mg} / \mathrm{kg}$ IV. Patients were intubated with oral cuffed endotracheal tube of appropriate size. Anaesthesia was maintained with a mixture of $50 \%$ of $\mathrm{O}_{2}, 50 \% \mathrm{~N}_{2} \mathrm{O}$ and isoflurane $1 \%$. Muscle relaxation was achieved with intermittent doses of atracurium. Hypotension, defined as fall in blood pressure $>20 \mathrm{mmHg}$ from the baseline was treated with IV mephentermine $6 \mathrm{mg}$. Bradycardia, defined as heart rate $<40$ beats/min was treated with atropine $0.6 \mathrm{mg}$ IV. At the completion of the surgery with aseptic precaution, $10 \mathrm{~mL}$ of study solution was infiltrated into subcutaneous tissue on either side of the surgical incision by an anaesthesiologist who was blinded to the drug administered.

Residual neuromuscular block was reversed with neostigmine $0.05 \mathrm{mg} / \mathrm{kg}$ and glycopyrrolate $0.01 \mathrm{mg} / \mathrm{kg} \mathrm{IV}$. Patients were extubated when they were fully conscious and breathed adequately. They were transferred to postanaesthesia care unit for further observation. An investigator blinded to group assignment evaluated postoperative VAS scores at 1, 2, 4, 6, 8, 12 and 24 hours, time of first rescue analgesia as per VAS score/patient demand, total analgesic consumption in $24 \mathrm{hrs}$. and adverse effects.

Rescue analgesia was administered with IM tramadol 50 $\mathrm{mg}$ to a maximum dose of $150 \mathrm{mg}$ either when VAS score was more than 5 or on patient demand. Patients were asked to express the degree of satisfaction and comfort they experienced with postoperative pain management. Vital parameters and side effects like nausea, vomiting, sedation, hypotension, dizziness, headache, dry mouth, allergic reactions and respiratory depression were recorded for 24 hours.

Data was analysed using statistical package for the Social Sciences (SPSS) version 15 (SPSS Inc., Chicago, IL). AndersonDarling test and Modified Levene's test respectively were used to compare normality and variance of data. Independent T-test (ANOVA of means) was used to compare continuous data between groups. Comparison of nominal data was done using chi-square analysis and ordinal data using MannWhitney test. $\mathrm{P}$ value $<0.05$ was considered statistically significant. Sample size for the study was estimated by taking into consideration the results of a study by Donaldi et al, Journal of Neuroanaesthesiology and Critical Care 2014. The effect size calculated from the results of that study was found to be 1 . In the power analysis by $\mathrm{G}$ power, the sample size required was found to be 50 with $\alpha=0.05$, power of $(1-\beta)=$ 0.95 and as dropout cases would be expected due to extended duration of surgery, sample size of 64 was selected for study (32 patients in each group).

\section{RESULTS}

Demographic data of patients in two groups were comparable with respect to ASA status, age, sex, weight and duration of the surgery, which was not significant (Table 1).

Mean postoperative VAS scores at $4^{\text {th }} \mathrm{hr}$ in Groups B and BM were 5.09 and 2.91 ( $\mathrm{p}=0.000 \mathrm{HS})$, at $6^{\text {th }} \mathrm{hr}$. VAS scores in Group B and BM were 4.31 and 3.34 ( $\mathrm{p}=0.039 \mathrm{Sig}$ ), at $24^{\text {th }} \mathrm{hr}$ VAS scores in Group B and BM were 4.31 and $3.44(p=0.018$ Sig). Group BM had lower VAS scores and better postoperative pain relief at $4^{\text {th }}, 6^{\text {th }}$ and $24^{\text {th }}$ hrs. when compared to Group B (Graph 1).

The mean time of first rescue analgesic in Group B and Group BM were 4.29 hrs. ( \pm 1.04$)$ and 6.91 hrs. ( \pm 1.65$)$ respectively ( $p=0.000 \mathrm{HS}$ ) (Graph 2 ).

$68.8 \%$ of patients in Group B demanded first analgesic within 4 - 5 hrs., $65.6 \%$ of patients in Group BM demanded first analgesic after 6 - 8 hrs. All patients in Group B required rescue analgesia within 7 hrs., whereas 20 patients in Group $\mathrm{BM}$ required rescue analgesia by the end of $7 \mathrm{hrs}$. (Table 2).

Total tramadol consumption in postoperative period was more in Group B compared to Group BM. The mean total requirement in Group B and BM was $175.00 \mathrm{mg}( \pm 38.10)$ and $119.53 \mathrm{mg}( \pm 47.83)$ respectively, ( $p=0.000$ HS). In Group B, 
84.4\% patients required 150 - $200 \mathrm{mg}$ of tramadol, while in Group BM $81.3 \%$ patients required 75 to $150 \mathrm{mg}$ tramadol (Graph 3).

7 patients (21.9\%) in Group B and 11 patients (34.4\%) in Group BM had nausea and vomiting, (P > 0.05 NS) (Graph 4). Hypotension was present in both the groups, but was not significant ( $p>0.05 \mathrm{NS}$ ) (Graph 5). There were no serious complications such as bradycardia, arrhythmias, desaturation and respiratory depression.

\begin{tabular}{|l|c|c|}
\hline \multicolumn{1}{|c|}{ Parameters } & Group B & Group BM \\
\hline 1. Age (Yrs.) & $47 \pm 5.61$ & $49 \pm 4.21$ \\
\hline 2. Sex M/F & $\mathrm{M}=18, \mathrm{~F}=14$ & $\mathrm{M}=16, \mathrm{~F}=16$ \\
\hline 3. Weight (kg) & $52 \pm 6.43$ & $55 \pm 5.43$ \\
\hline 4. Duration of Surgery (min.) & $80 \pm 18.51$ & $85 \pm 13.17$ \\
\hline \multicolumn{2}{|c|}{ Table 1. Demographic Parameters } \\
\hline
\end{tabular}

Demographic data of patients $(\mathrm{p}<0.001 \mathrm{NS})$

\begin{tabular}{|c|c|c|c|}
\hline Group & $\begin{array}{c}\text { Number } \\
\text { of Patients }\end{array}$ & $\begin{array}{c}\text { First Analgesic } \\
\text { Time hrs. }\end{array}$ & Percentage \\
\hline & 1 & 2 & 3.1 \\
\hline $\mathrm{B}$ & 6 & 3 & 18.8 \\
\hline & 11 & 4 & 34.4 \\
\hline & 11 & 5 & 34.4 \\
\hline & 2 & 6 & 6.3 \\
\hline & 1 & 7 & 3.1 \\
\hline & Total 32 & & $\mathbf{1 0 0}$ \\
\hline BM & 1 & 3 & 3.1 \\
\hline & 2 & 4 & 6.3 \\
\hline & 3 & 5 & 9.4 \\
\hline & 4 & 6 & 12.5 \\
\hline & 12 & 7 & 37.5 \\
\hline & 5 & 8 & 15.6 \\
\hline & 3 & 9 & 9.4 \\
\hline & 2 & 10 & 6.3 \\
\hline & Total 32 & & $\mathbf{1 0 0}$ \\
\hline Table 2. Percentage and Times of First Rescue Analgesia \\
\hline
\end{tabular}

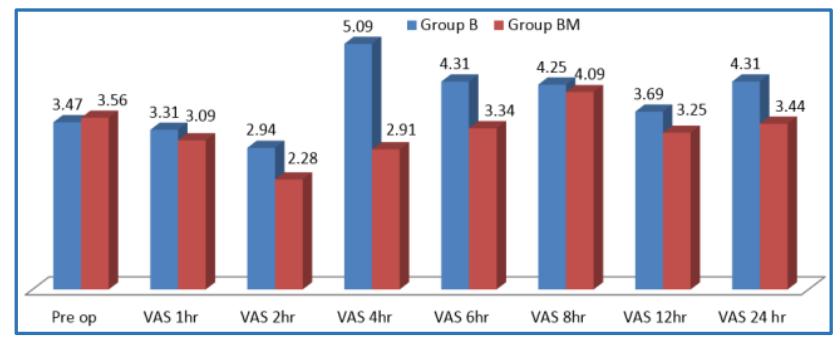

Graph 1. Preoperative and Postoperative VAS Scores

VAS at $4^{\text {th }} \mathrm{hr} .(\mathrm{p}=0.000 \mathrm{HS})$, VAS at $6^{\text {th }} \mathrm{hr} .(\mathrm{p}=0.039 \mathrm{Sig})$, VAS at $24^{\text {th }} \mathrm{hr} .(\mathrm{p}=0.018 \mathrm{Sig})$.

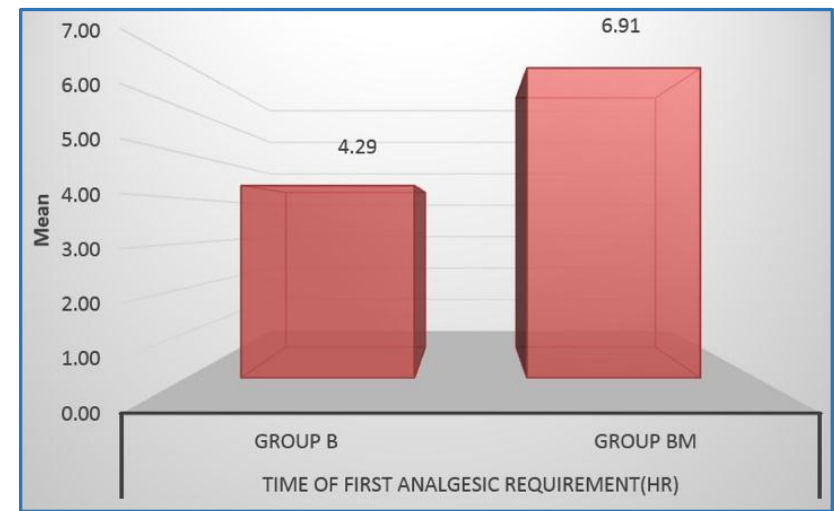

Graph 2. Time of Administration of First Rescue Analgesic

$\mathrm{P}=(0.000 \mathrm{HS})$

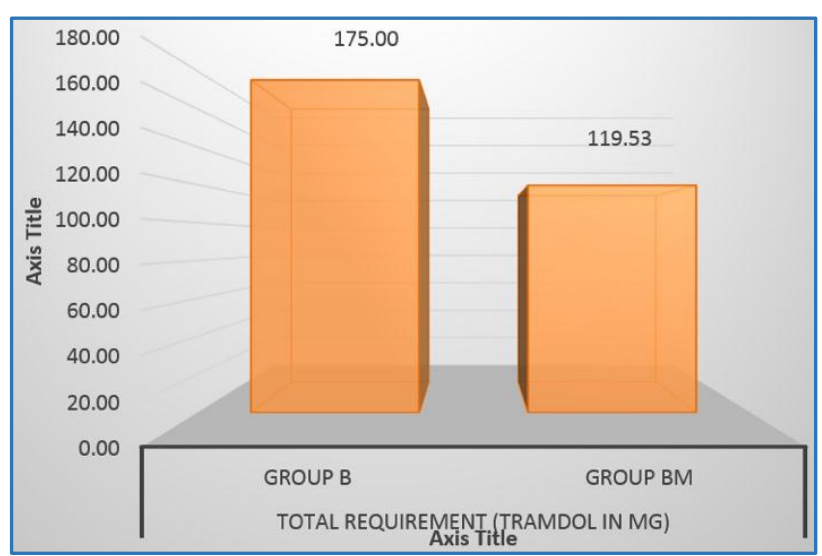

Graph 3. Total Requirement of Tramadol (mg) in 24 Hours $(\mathrm{p}=0.000 \mathrm{HS})$

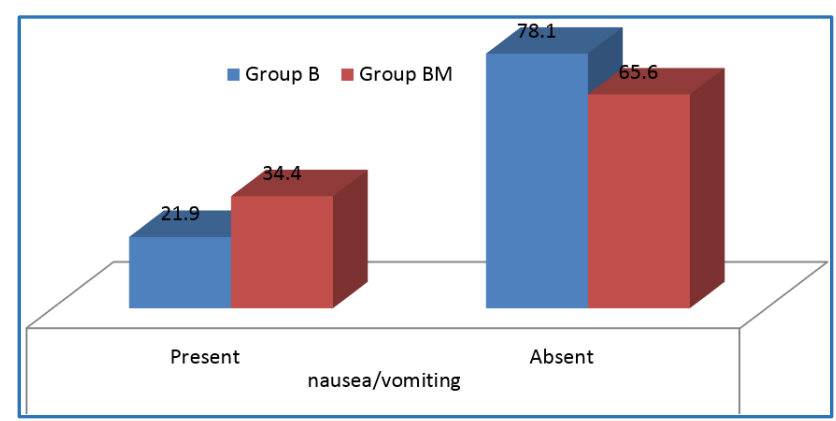

Graph 4. Nausea/Vomiting

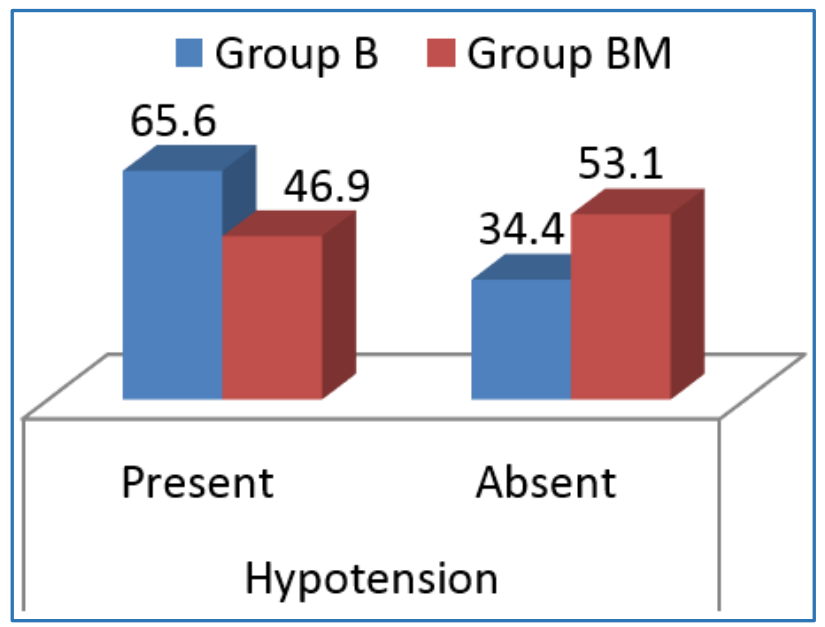

Graph 5. Hypotension 


\section{DISCUSSION}

Direct application of local anaesthetics to wound can provide analgesia through two different mechanisms. Transmission of pain from nociceptive afferents in the wound surface is directly blocked by local anaesthetics by binding to fast sodium channels within the axon membrane and action potential propagation is inhibited. Secondly, local inflammatory response to injury, which is responsible for sensitising nociceptive receptors and contribute to pain and hyperalgesia are also blocked by local anaesthetics. The release of inflammatory mediators from neutrophils, neutrophil adhesion to the endothelium, formation of free oxygen radicals and oedema formation are effectively reduced by local anaesthetic infiltration. ${ }^{4}$

Magnesium sulphate is a non-competitive N-methyl-Daspartate (NMDA) receptor antagonist ${ }^{5}$ that blocks ion channels in a voltage-dependent fashion. ${ }^{6}$ NMDA receptor antagonists prevent central sensitisation induced by peripheral nociceptive stimulation, and abolish hypersensitisation by blocking dorsal horn of NMDA receptor activation induced by excitatory amino acid (EAA) transmitters such as glutamate and aspartate. ${ }^{3}$

Magnesium is widely used in the perioperative setting and has shown to decrease the anaesthesia and analgesia requirements effectively.7,8,9 Magnesium is administered as co-analgesic with peripheral blocks to prolong the action of local anaesthetics. Administration of intravenous magnesium sulphate has disadvantages of prolonging action of neuromuscular blocking agents ${ }^{10}$ and increasing sedation. ${ }^{11}$ Subcutaneous infiltration of magnesium sulphate with bupivacaine, ropivacaine or levobupivacaine has shown to prolong the duration of action of local anaesthetic drugs. ${ }^{12,13,14,15}$

Donaldi PK et al compared local infiltration of $20 \mathrm{~mL}$ bupivacaine $0.25 \%$ alone and bupivacaine $0.25 \%(10 \mathrm{~mL})$ with magnesium sulphate $500 \mathrm{mg}(1 \mathrm{~mL})$ in $9 \mathrm{~mL}$ of normal saline for pain relief following laminectomy and observed that administration of first rescue analgesia was delayed in magnesium group $7.78 \pm 1.350 \mathrm{hrs}$. compared to bupivacaine group $4.62 \pm 0.997$ hrs. ( $<<0.0001)$. Tramadol consumption was significantly higher in bupivacaine group (202.5 \pm 76.9 $\mathrm{mg}$ ) compared to magnesium group $(117.5 \pm 6.4)(\mathrm{p}<$ 0.0001 ) and concluded that bupivacaine plus magnesium sulphate achieved better pain control. ${ }^{13}$

Kundra et al compared the efficacy of $750 \mathrm{mg}$ of magnesium sulphate plus ropivacaine $0.75 \%(150 \mathrm{mg}$ ) with ropivacaine $0.75 \%$ (150 $\mathrm{mg}$ ) alone for local subcutaneous wound infiltration, at the conclusion of caesarean section under spinal anaesthesia. The requirement of first intravenous rescue analgesia with tramadol was similar in both groups ( $p=0.279 \mathrm{NS}$ ), but there was significant delay in the need for $2^{\text {nd }}$ and $3^{\text {rd }}$ doses of rescue analgesics in magnesium group compared to ropivacaine group $(\mathrm{p}=0.034$ and $p=0.031$, respectively). The number of patients requiring $2^{\text {nd }}, 3^{\text {rd }}$ and $4^{\text {th }}$ doses of rescue analgesia and the total analgesic requirement in 24 hours were significantly greater in ropivacaine group compared to magnesium group $(\mathrm{p}=$ 0.01). ${ }^{14}$

Eldaba et al infiltrated the wound continuously with $0.25 \%$ bupivacaine $5 \mathrm{~mL} / \mathrm{hr}$ or $0.125 \%$ bupivacaine with 50 magnesium sulphate or normal saline $(0.9 \%)$ at the conclusion of the surgery. Postoperative pain was higher in bupivacaine group compared to magnesium group ( $\mathrm{p}<$ 0.0001). Time to first patient controlled analgesic requirement in bupivacaine group was $119 \pm 28$ mins, magnesium group was $175 \pm 36$ mins and control group was $100 \pm 24$ mins, $(p<0.0001)$ between bupivacaine and magnesium group, $(p=0.0017)$ between magnesium and control group and $(\mathrm{p}<0.0001)$ between bupivacaine and control group. During movement, VAS scores were significantly higher in the control group at 2, 4, 12, $24 \mathrm{hrs}$. post-operatively compared to other groups ( $p<0.0001) .15$ There was significant decrease in morphine consumption in the magnesium group $(\mathrm{p}<0.0001)$ and bupivacaine group ( $\mathrm{p}$ $<0.0001$ ) when compared to control group.

In our study mean postoperative VAS scores in Groups B and $\mathrm{BM}$ at $4^{\text {th }} \mathrm{hr}, 6^{\text {th }} \mathrm{hr}$ and $24^{\text {th }} \mathrm{hr}$ were 5.09 and 2.91 ( $p=0.000$ HS), 4.31 and 3.34 ( $p=0.039$ Sig) and 4.31 and 3.44 ( $p=0.018$ Sig) respectively. Group BM had lower VAS scores and statistically significant postoperative pain relief at $4^{\text {th }}, 6^{\text {th }}$ and $24^{\text {th }}$ hrs. when compared to Group B. The mean time to first rescue analgesic was significantly delayed in Group BM 6.91 hrs. $( \pm 1.65)$ ( $p=0.000$ HS) when compared to Group B 4.29 hrs. $( \pm 1.04)$; $68.8 \%$ of patients in Group B demanded first analgesic within $4-5$ hrs. and $65.6 \%$ of patients in Group BM demanded first analgesic after a delay of 6 - 8 hrs. Total tramadol consumption in 24 hrs. was higher in Group B compared to Group BM. The mean total requirement of tramadol in Group B and BM was $175.00 \mathrm{mg}( \pm 38.10)$ and $119.53 \mathrm{mg}( \pm 47.83)$ respectively, $(\mathrm{p}=0.000 \mathrm{HS})$.

From the comparative studies, it is evident that addition of magnesium sulphate to different local anaesthetics for wound infiltration prolongs the duration of postoperative analgesia and consumption of rescue analgesics. Our study cannot be generalised to all patients as we have studied only ASA Grade I and II without any comorbidity and study period was limited to only $24 \mathrm{hrs}$. Larger series of study is required to assess the role of magnesium as adjuvant to local anaesthetics and its long-term effects.

\section{CONCLUSION}

Addition of magnesium sulphate to bupivacaine for local wound infiltration at the conclusion of surgery enhances effective analgesia in the postoperative period with lower postoperative VAS scores. The timing of the first rescue analgesic is deferred leading to decreased total rescue analgesic consumption in first twenty-four hours. The technique is simple, relatively non-invasive, quickly performed, cost effective and is useful as component of multimodal analgesia, especially when epidural analgesia and major regional blocks cannot be advocated.

\section{REFERENCES}

[1] Rawal N. Postoperative pain management - good clinical practice, general recommendations and principles for successful pain management. http://www.esraeurope.org/Postoperative Pain Management. 
[2] Dahl JB, Moiniche S, Kehlet H. Wound infiltration with local anaesthetics for postoperative pain relief. Acta Anaestheiol Scand 1994;38(1):7-14.

[3] Woolf CJ, Thompson SW. The induction and maintenance of central sensitization is dependant on $\mathrm{N}$-methyl-D-aspartic acid receptor activation: implications for the treatment of post-injury pain hypersensitivity states. Pain 1991;44(3):293-9.

[4] Moiniche S, Mikkelsen S, Wetterslev J, et al. A qualitative systematic review of incisional local anaesthesia for post-operative pain relief after abdominal operations. Br J Anaesth 1998;81(3):377-3.

[5] McBain CJ, Mayer ML. N-methyl-D-aspartic acid receptors: structure and function. Physiol Rev 1994;74(3):723-60.

[6] Mayer ML, Westbrook GL, Guthrie PB. Voltagedependant block by Mg2+ of NMDA responses in spinal cord neurones. Nature 1984;309(5965):261-3.

[7] Albrecht E, Kirkham KR, Liu SS, et al. Peri-oprative intravenous administration of magnesium sulphate and postoperative pain: a meta-analysis. Anaesthesia 2013;68(1):79-90.

[8] Akarsu M, Tuncer S, Reisli $\mathrm{R}$, et al. The role of magnesium in preventing postoperative hyperalgesia. Agri 2012;24(1):15-22.

[9] Dabbagh A, Elyasi H, Razavi SS, et al. Intravenous magnesium sulphate for oostoperative pain in patients undergoing lower limb orthopedic surgery. Acta Anaesthesiol Scand 2009;53(8):1088-91.
[10] Kussman B, Shorten G, Uppington J, et al. Administration of magnesium sulphate before rocuronium: effects on speed of onset and duration of neuromuscular block. Br J Anaesth 1997;79(1):122-4.

[11] Kiran S, Gupta R, Verma D. Evaluation of a single-dose of intravenous magnesium sulphate for prevention of postoperative pain after inguinal surgery. Indian J Anaesth 2011;55(1):31-5.

[12] Tauzin-Fin P, Sesay M, Svartz L, et al. Wound infiltration with magnesium sulphate and ropivacaine mixture reduces postoperative tramadol requirements after radical prostatectomy. Acta Anaesthesiol Scand 2009;53(4):464-9.

[13] Donadi PK, Srilata M, Ramachandran G. Comparison of bupivacaine and bupivacaine plus magnesium sulphate infiltration for postoperative analgesia in patients undergoing lumbar laminectomy: A prospective randomised double-blinded controlled study. Journal of Neuroanaesthesiology \& Critical care 2014;1(3):183-7.

[14] Kundra S, Singh RM, Singh G, et al. Efficacy of magnesium sulphate as adjunct to ropivacaine in local infiltration for postoperative pain following lower segment cesarean section. J Clin Diagn Res 2016;10(4):UC18-UC22.

[15] Eldaba AA, Amr YM, Sobhy RA. Effect of wound infiltration with bupivacaine or lower dose bupivacaine/magnesium versus placebo for postoperative analgesia after cesarean section. Anaesthesia Essays and Researches 2013;7(3):336-40. 